\title{
ANALISIS TITIK IMPAS CABE JAMU (Piper retrofractum Vahl) LOKAL MADURA
}

\author{
Disusun Oleh : \\ Kustiawati Ningsih \\ Program Studi Agribisnis, Fakultas Pertanian, Universitas Islam Madura, \\ Kompleks Ponpes Miftahul Ulum Bettet, Pamekasan, Madura, Kode Pos 69351, Indonesia \\ E-mail : ningsihkustiawati@yahoo.com
}

\begin{abstract}
ABSTRAK
Penelitian ini bertujuan adalah untuk mengidentifikasi total biaya yang dikeluarkan, total penerimaan yang diperoleh, dan jumlah produksi cabe jamu pada saat BEP dicapai. Penelitian ini dilakukan pada usahatani cabe jamu di Desa Pekandangan Sangra, Kecamatan Bluto, Kabupaten Sumenep. Desa Pekandangan Sangra ini dipilih dengan pertimbangan bahwa Desa Pekandangan Sangra adalah salah satu sentra produksi cabe jamu yang produksinya memiliki segmen pasar yang luas. Penelitian ini dilakukan pada bulan Nopember sampai Desember 2012. Hasil analisis menunjukkan bahwa BEP pada usahatani cabe jamu adalah sekitar 47,06 kg atau dengan pengeluaran sekitar Rp 3.515.697,5 per musim tanam.
\end{abstract}

Kata kunci : : Analisis Titik Impas, Cabe Jamu

\section{BREAK-EVEN POINT ANALYSIS HERBS CHILLIES (Piper retrofractum Vahl) LOCAL MADURA}

\begin{abstract}
The aim of this study is to identify the total cost, total revenue received, and the amount of herb chillies production at BEP achieved. The research was conducted on farming of herbs chillies in Pekandangan Sangra Village, Bluto District, Sumenep Regency. Pekandangan Sangra village have been selected on the basis that Pekandangan Sangra village is one of the herbs chillies production center whose production has a broad market segment. This study was conducted from November to December 2012. The results show that the BEP on farming of herbs chili is about $47.06 \mathrm{~kg}$ or by spending about IDR 3,515,697.5 per growing season.
\end{abstract}

Keywords $\quad$ : Break Event Point Analysis, Herb Chillies

\section{PENDAHULUAN}

Sampai dewasa ini sektor pertanian masih merupakan sektor penting dalam pembangunan perekonomian nasional. Hal ini berdasarkan fakta dimana masih besarnya sumbangsih sektor pertanian terhadap pangsa share PDB, penyerapan tenaga, devisa dan ketahanan pangan nasional. Menurut Hery Toiba dan Rosihan Asmara (2005), dalam perkembangannya dimasa yang akan datang sektor pertanian masih dianggap sebagai sektor terpenting dalam pembangunan ekonomi secara keseluruhan sehingga sektor ini dituntut untuk dapat bergerak lebih dinamis mengikuti gerak perubahan domestik dan global.

Dalam arti luas, pembangunan sektor pertanian mencakup tanaman pangan, perkebunan, perikanan dan peternakan yang saat ini masih menjadi sektor andalan di Indonesia. Karena sektor pertanian dalam arti luas ini masih menjadi salah satu sektor unggulan yang mampu memberikan kontribusi yang tinggi bagi pembangunan daerah, maka sejalan dengan tujuan pembangunan pertanian, 
salah satu kebijaksanaan pembangunan sektor pertanian adalah mengembangkan sub sektor perkebunan yang diarahkan pada perkembangan perkebunan rakyat. Sub sektor perkebunan ini masih diharapkan sebagai lapangan usaha yang menyerap banyak tenaga kerja, penyedia bahan baku untuk bahan industri pengolahan dan berperan dalam kelestarian lingkungan hidup. Karena itu usaha untuk mengembangkan sub sektor ini perlu terus ditingkatkan.

Salah satu komoditi perkebunan yang mampu mendukung berdirinya beberapa industri adalah tanaman cabe jamu (Piper retrofractum Vahl). Disamping itu, jika mengacu pada kondisi agroklimat Kabupaten Pamekasan yang sebagian besar lahan kering dengan tingkat kesuburan rendah, maka dengan pertimbangan sumberdaya yang terbatas tersebut komoditas yang cukup sesuai untuk dibudidayakan adalah tanaman cabe jamu (PiperRetrofractum Vohl).

Tanaman cabe jamu (Piper Retrofractum Vohl) atau sering disebut juga cabe jawa, termasuk famili Piperacea yang memiliki sifat hampir sama dengan tanaman lada (Piper Ningrum) dan tanaman sirih (Piper Bettle). Saat ini jawa timur merupakan pemasok utama kebutuhan bahan baku obat tradisional, baik untuk kebutuhan dalam negeri maupun bahan baku ekspor dengan negara tujuan antara lain singapura, Malaysia, Hongkong dan India yang permintaannya sejak tahun 1997 terus meningkat (Suyanto, 2002).

Budidaya tanaman cabe jamu

(Piper Retrofractum Vohl) merupakan suatu peluang usaha yang cukup memberikan harapan karena permintaan cabe jamu kering semakin lama semakin meningkat dan ternyata produksi obat atau jamu tradisional tidak hanya dikonsumsi oleh masyarakat dalam negeri tetapi juga oleh konsumen luar negeri. Peningkatan produksi jamu olahan pabrik jamu antara lain disebabkan oleh pesatnya pertumbuhan jumlah industrinya dan semakin tingginya minat masyarakat pada jamu tradisional karena dipandang lebih aman. Bahkan trend pengolahan akhirakhir ini cenderung kembali pada tanaman yang digunakan secara tradisional. Dengan meningkatnya jumlah industri jamu dan produksi jamu tradisional secara langsung akan meningkatkan permintaan cabe jamu. Menurut data dari Dinas Kehutanan dan Perkebunan Sumenep (2012) hasil produksi Cabe Jamu dari 8500 ton. Namun produksi cabe jamu belum dapat memenuhi permintaan tersebut, karena produksinya masih rendah (Ruhnayat dan Taryono, 2008).

Produksi cabe jamu di Desa Pekandangan Sangra, Kecamatan Bluto, Kabupaten Sumenep relatif stabil dengan produksi rata-rata sebesar $250 \mathrm{~kg} / \mathrm{ha}$ dan petani cabe jamu telah memperoleh keuntungan yang cukup. Namun besarnya keuntungan tersebut belum diketahui secara pasti, karena sampai saat ini belum pernah ada penelitian tentang masalah tersebut, khususnya pada usahatani cabe jamu. Dilain pihak dengan mengetahui besarnya biaya produksi pada satuan unit produksi tertentu, melalui Analisis Titik Impas (BEP), seseorang petani akan dapat mengetahui besarnya keuntungan atau kerugian yang diperoleh dari hasil penjualan produksinya.

\section{TUJUAN PENELITIAN}

Penelitian ini bertujuan untuk
mengetahui besarnya biaya yang
dikeluarkan, besarnya penerimaan yang
diperoleh serta jumlah unit produksi dalam
usaha tani cabe jamu pada saat usaha
tersebut mencapai titik impas.

\section{METODE PENELITIAN}

\section{A. Lokasi dan Waktu Penelitian}

Penelitian ini dilakukan di Desa Pekandangan Sangra, Kecamatan Bluto, Kabupaten Sumenep, Madura, Jawa Timur. Pemilihan lokasi tersebut dilakukan secara sengaja (purposive) dengan pertimbangan bahwa Desa Pekandangan 
Sangra merupakan salah satu sentra produksi cabe jamu di Kabupaten Sumenep.

\section{B. Jenis Data}

Data yang digunakan adalah data primer dan data sekunder. Data primer diperoleh dari pengamatan di lapangan dan wawancara dengan petani cabe jamu yang meliputi jumlah input dan biayanya, jumlah output beserta harga jualnya. Semua data primer dikumpulkan dengan cara survei, dan mewawancarai responden secara langsung dengan menggunakan daftar pertanyaan (kuisioner) yang telah dipersiapkan sebelumnya (Singarimbun dan Effendi, 1987).

Sedangkan data sekunder diperoleh dari Departemen Kehutanan dan Perkebunan Kabupaten Pamekasan, perpustakaan UIM Pamekasan dan instansi-instansi terkait lainnya.

\section{Penentuan Sampel}

Penentuan sampel menggunakan rumus :

$$
n=\frac{N}{1+N(d)}
$$

Keterangan :

$$
\begin{array}{lll}
\mathrm{n} & =\text { Besar Sampel } & \\
\mathrm{N} & =\text { Besar populasi } \\
\mathrm{d} & =\quad \text { ketetapan } & \text { yang }
\end{array}
$$$$
\text { diinginkan }(0,01)
$$

dimana jumlah populasi petani cabe jamu di Desa Muncek adalah 80 orang, sehingga sampel dalam penelitian ini adalah :

$$
\begin{aligned}
& n=\frac{N}{1+N(d)} \\
& n=\frac{80}{1+80(0,01)} \\
& n=\frac{80}{1,8}=44,44 \quad= \\
& \text { (pembulatan) }
\end{aligned}
$$

Setelah jumlah populasi dalam penelitian ini dimasukkan dalam rumus maka didapat jumlah sampel sebanyak 45 orang (kepala keluarga).

\section{Analisis Data}

Analisis data yang digunakan untuk mengetahui tujuan yang ingin dicapai yaitu :

Analisis titik impas, secara matematis :

$$
\begin{aligned}
& \mathrm{TR}=\mathrm{TC} \\
& \mathrm{TR}=\mathrm{P} \times \mathrm{Q} \\
& \mathrm{TC}=\mathrm{TFC}+\mathrm{TVC} \\
& \mathrm{TC}=\mathrm{TFC}+(\mathrm{AVC} \times \mathrm{Q})
\end{aligned}
$$

Persamaan di atas dapat disederhanakan menjadi :

$$
\begin{aligned}
& P \times Q=T F C+(A V C \times Q) \\
& P \times Q-(A V C \times Q)=T F C \\
& Q(P-A V C)=T F C
\end{aligned}
$$

Dengan demikian diperoleh rumus titik impas dalam satuan unit produk sebagai berikut :

$$
Q=\frac{T F C}{P-A V C}
$$

Selanjutnya untuk menghitung titik impas dalam satuan rupiah, maka satuan unit (Q) dikalikan dengan harga jual per unit (P) dengan persamaan sebagai berikut :

$$
\begin{aligned}
Q . P & =\frac{T F C . P}{P . A V C} \\
Q . P & =\frac{T F C}{P-(A V C) P}
\end{aligned}
$$

Maka diperoleh rumus titik impas dalam satuan rupiah sebagai berikut :

$$
Q . P=\frac{T F C}{1-(A V C) / P}
$$

Keterangan :

$\mathrm{TR}=$ Total Penerimaan (Total revenue) (Rp)

$\mathrm{TC}=$ Total Biaya (Total Cost) (Rp)

TFC = Total Biaya Tetap (Total Fixed

Cost) (Rp) 
TVC = Total Biaya Variabel (Total

Variabel Cost) (Rp)

AVC = Rata - rata Biaya Variabel Per

Unit (Average Variabel Cost)

$\mathrm{Q} \quad=$ Total Produksi dalam Usaha

(Quantity) (Per Kg)

$\mathrm{P} \quad=$ Harga Jual Per unit (Price) $(\mathrm{Rp})$

\section{HASIL DAN PEMBAHASAN \\ A. Hasil Produksi Usahatani Cabe Jamu Lokal Madura}

Hasil produksi adalah satu fungsi manajemen yang penting dalam operasi suatu usaha tani. Dari total keseluruhan responden, petani cabe jamu lokal memproduksi cabe jamu rata-rata $250 \mathrm{~kg}$.

\section{B. Biaya Produksi Usahatani Cabe Jamu Lokal Madura}

Biaya dalam usahatani cabe jamu meliputi biaya tetap dan biaya variabel. Biaya tetap meliputi, sewa lahan, pajak lahan dan alat-alat pertanian yang tidak habis pakai dalam satu periode produksi.

\section{Biaya Tetap}

a. Sewa Lahan

Sewa lahan merupakan besarnya keluaran biaya yang dilakukan oleh petani dalam proses budidaya tanaman cabe jamu. Walaupun lahan milik sendiri biaya lahan dihitung berdasarkan sewa rata-rata yang berlaku. Besarnya biaya sewa lahan rata-rata per hektar dalam proses budidaya cabe jamu sebesar Rp. 3.5000.000,-

b. Pajak Lahan

Pajak adalah biaya yang dikeluarkan oleh petani untuk membayar pajak terhadap lahan yang digunakan untuk usahatani. Besarnya pajak rata-rata per hektar sebesar Rp. 52.500,-

c. Alat-Alat Pertanian

Biaya alat-alat pertanian dalam budidaya cabe jamu yang termasuk biaya tetap adalah alat-alat pertanian yang tidak habis dipakai dalam satu periode budidaya tanaman cabe jamu. Seperti cangkul, ember, sabit dan lain-lain. Besarnya biaya rata-rata per hektar untuk alat-alat pertanian sebesar Rp. 1.500.000,-

Biaya tetap yang dikeluarkan petani rata-rata untuk satu hektar sebesar Rp. 2.812.558,-

\section{Biaya Variabel}

a. Benih

Benih atau bibit cabe jamu dalam usahatani ini dibeli dari petani lain yang membudidayakan. Biaya rata-rata per hektar untuk pembelian benih sebesar Rp. 350.000,-

b. Pupuk

Pupuk Biaya dalam usahatani cabe jamu terdiri atas tiga jenis yaitu pupuk kandang, Urea dan ZA. Besar biaya ratarata yang dikeluarkan untuk petani dalam pengadaan pupuk adalah sebagai berikut, untuk pupuk kandang sebesar Rp. 3.000.000,-, untuk pupuk urea sebesar Rp. 180.000,- dan untuk pupuk ZA sebesar Rp. 560.000,-

c. Tenaga Kerja

Biaya tenaga kerja adalah keluaran biaya yang dilakukan oleh petani untuk biaya tenaga kerja. Dalam usahatani cabe jamu ini biaya tenaga kerja meliputi pengolahan tanah, Pemupukan dan perawatan. Besarnya biaya rata-rata per hektar yang dikeluarkan petani untuk biaya tenaga kerja adalah sebagai berikut : untuk biaya pengolahan tanah sebesar Rp. 1.500.000,-, untuk biaya pemupukan sebesar Rp. 750.000,- dan untuk perawatan sebesar Rp. 500.000,-

Total biaya variabel yang dikeluarkan oleh petani dalam budidaya tanaman cabe jamu rata-rata untuk setiap hektar sebesar Rp. 3.807.600,-

\section{Penerimaan dan Pendapatan}

Pendapatan petani merupakan ukuran penghasilan yang diterima oleh petani dari usahataninya. Dalam analisis usahatani, pendapatan petani digunakan sebagai indikator penting karena merupakan sumber utama dalam mencukupi kebutuhan seharihari (Parwati, 2007). 
Pendapatan merupakan hasil akhir dari penerimaan dikurangi dengan total biaya yang dikeluarkan dalam suatu produksi, sedangkan total penerimaan adalah produksi dikalikan dengan harga produksi (Soekartawi, 2001:24).

Jumlah penerimaan dan pendapatan yang diperoleh petani cabe jamu tercantum pada Tabel 1.

Tabel 1. Penerimaan, Biaya dan Pendapatan Rata-Rata Usahatani Cabe Jamu
Dari hasil perhitungan $\mathrm{BEP}_{\text {unit }}$ usahatani cabe jamu di Desa Pekandangan Sangra, Kecamatan Bluto, Kabupaten Sumenep, menyatakan bahwa petani akan mencapai titik impas atau Break Event Point (BEP) apabila tingkat produksinya sebanyak 47,06 kg.

Jika dihitung dalam rupiah menjadi Rp. 3.515.697,5-. Penghitungan titik impas dalam rupiah adalah

$$
Q . P=\frac{T F C}{1-\frac{A V C}{P}}
$$

\begin{tabular}{|c|c|c|c|}
\hline No & Uraian & Japplah & 2.812 .558 \\
\hline 1 & Penerimaan (Rp) & 10.437 .500 & $1-\frac{15.230,4}{75000}$ \\
\hline 2 & Total Biaya (Rp) & 6.620 .158 & 2.812 .558 \\
\hline 3 & Pendapatan (Rp) & 3.817 .342 & $1-0,20$ \\
\hline Sumb & er : Data Primer diolah, 2012 & $=$ & $\frac{2.812 .558}{0,80}$ \\
\hline
\end{tabular}

\section{Analisis Titik Impas}

Kelayakan usahatani dapat dilanjutkan apabila memberikan nilai ekonomi atau menguntungkan. Keuntungan didapat setelah diketahui titik impas atau Break Event Point (BEP) dari usahatani tersebut. Sesuai data yang kami peroleh dari petani cabe jamu, maka BEP dalam satuan unit produk (kg) dicari dengan rumus :

$$
B E P_{\text {unit }}=\frac{T F C}{P-A V C}
$$

Diketahui :

$$
\begin{array}{ll}
\text { TFC } & =\text { Rp. 2.812.558,- (biaya tetap) } \\
\mathrm{P} & =\text { Rp. 75.000,- (harga jual per kg) } \\
\text { TVC } & =\text { Rp. 3.807.600,- (biaya variabel) } \\
\mathrm{Q} & =250 \mathrm{~kg} \text { (produksi) }
\end{array}
$$

Biaya variabel per kg (AVC) = Rp. 3.807.600,- / 250

$$
\begin{aligned}
\mathrm{BEP}_{\text {unit }} & =\frac{2.812 \cdot 558}{75.000-15.230,4} \\
& =47,06 \mathrm{~kg}
\end{aligned}
$$$$
=\text { Rp. 15.230,4,- }
$$

$$
=3.515 .697,5
$$

Hasil perhitungan tersebut, digambarkan dalam bentuk grafik sebagai berikut :

TR, TC (Rp)

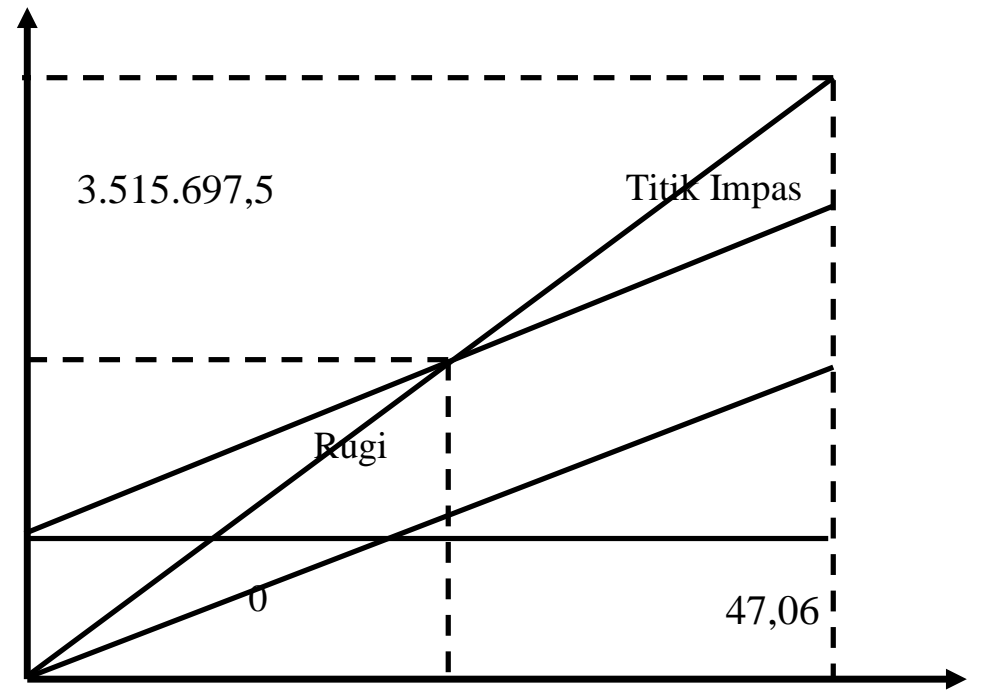

Gambar 1. Titik Impas Usahatani Cabe Jamu di Desa Lenteng Timur, Kecamatan Lenteng, Kabupaten Pamekasan (2012) 
Dari hasil perhitungan dan gambar grafik Titik Impas tersebut diketahui, bahwa untuk mencapai titik impas (BEP), petani cabe jamu harus memproduksi cabe jamu sebanyak 47,06 kg dengan harga jual Rp 75.000 per kg. Dalam posisi ini, maka total biaya produksi akan sama besar dengan penerimaan, yaitu sebesar Rp 3.515.697,5.

\section{KESIMPULAN DAN SARAN \\ A. Kesimpulan}

Berdasarkan hasil analisis danpembahasan yang telah diuraikan sebelumnya, maka penelitian ini memberi kesimpulan sebagai berikut :

1. Biaya tetap yang dikeluarkan untuk usahatani cabe jamu sebesar Rp 2.812.558,- per musim tanam.

2. Biaya variabel untuk usahatani cabe jamu adalah sebesar Rp 3.807.600,per musim tanam.

3. Jumlah penerimaan untuk usahatani cabe jamu sebesar Rp 10.437.500,- per musim tanam.

4. Pendapatan yang diperoleh dari usahatani cabe jamu sebesar Rp. 3.817.342,- per musim tanam

5. Titik Impas (BEP) untuk usahatani cabe jamu yaitu sebanyak 47,06 kg, dengan rata-rata harga jual sebesar Rp. $75.000 / \mathrm{kg}$ diperoleh penerimaan sebesar Rp 3.515.697,5,- per musim tanam.

\section{B. Saran}

Mengingat bahwa pada dasarnya
usahatani cabe jamu telah cukup
menguntungkan, maka
meningkatkan besarnya keuntungan bisa
diupayakan dengan memproduksi di atas
titik impas melalui peningkatan jumlah
produksi tiap musim tanam dan
memperluas daerah pemasarannya.
Dengan demikian bisa diperoleh tingkat
permintaan yang lebih tinggi, sehingga
diharapkan memperoleh laba yang lebih
besar.

\section{DAFTAR PUSTAKA}

Dinas Kehutanan dan Perkebunan Sumenep. 2012. Sumenep dalam Angka. Pemerintah Daerah Kabupaten Sumenep.

Heri Toiba dan Rosihan Asmara, 2005. Model perencanaan program dan investasi pembangunan pertanian tanaman pangan nasional. Jurnal Agrivita Vol 27(3) hal 234-247.

Ruhnayat, Agus dan Taryono, 2008. Cabe Jawa. Penebar Swadaya. Jakarta.

Singarimbun, M. dan S. Effendi, 1987. Metode penelitian survei. Cetakan Keenam. LP3ES Jakarta.

Soekartawi, 2001. Agribisnis teori dan aplikasinya, CV. Rajawali Press, Jakarta.

Suyanto, 2002. Teknologi Budidaya Tanaman Cabe Jamu. 